\title{
Dual Orthogonal Feed Circular Polarization Array Antenna Using Microstrip Slot Feed Network
}

\author{
Quazi Delwar Hossain*, Md. Azad Hossain**, Muhammad Asad Rahman* \\ *Department of Electrical and Electronic Engineering, Chittagong University of Engineering \& Technology \\ **Department of Electronics and Telecommunication Engineering, Chittagong University of Engineering \& Technology
}

\begin{tabular}{|c|c|}
\hline Article Info & ABSTRACT \\
\hline Article history: & This paper presents a new circularly polarized microstrip array antenna using \\
\hline Received May 2, 2015 & $\begin{array}{l}\text { dual-orthogonal feed technique. The feed network for } 1 \times 2 \text { array is designed } \\
\text { using microstrip lines and slot lines by applving double-sided MIC concept }\end{array}$ \\
\hline Revised Aug 2, 2015 & effectively. The $90^{\circ}$ phase difference between two orthogonally feed signals \\
\hline Accepted Aug 17, 2015 & $\begin{array}{l}\text { is created by choosing appropriate feed point in the feed network to advance } \\
\text { one of the feed signals by quarter wave length }(\lambda / 4) \text { from other. Excellent }\end{array}$ \\
\hline Keyword: & $\begin{array}{l}\text { radiation performance is obtained from this proposed antenna with low cross } \\
\text { polar component. The impedance }(<-10 \mathrm{~dB}) \text { bandwidth of the array is } 9.1 \%\end{array}$ \\
\hline Array antenna & and the $3-\mathrm{dB}$ axial ratio bandwidth is $1.85 \%$ (from $9.905 \mathrm{GHz}$ to $10.09 \mathrm{GHz}$ ). \\
\hline Circular polarization & $\begin{array}{l}\text { The average gain is higher than } 9 \mathrm{dBiC} \text { over the } 3-\mathrm{dB} \text { AR bandwidth. The } \\
\text { relation between antenna dimensions and characteristics is also investigated }\end{array}$ \\
\hline Double-sided MIC & with a parametric analysis of the antenna. \\
\hline Dual-orthogonal feed & \\
\hline
\end{tabular}

Copyright (C) 2015 Institute of Advanced Engineering and Science. All rights reserved.

\section{Corresponding Author:}

Quazi Delwar Hossain,

Department of Electrical and Electronic Engineering,

Chittagong University of Engineering \& Technology,

Chittagong-4349, Bangladesh

Email: qdhossain@yahoo.com

\section{INTRODUCTION}

Circular polarization (CP) antennas are suitable for many microwave applications as it has ability to reduce polarization losses. Linearly polarized antennas need strict alignment between transmitter and receiver where as circularly polarized antennas can communicate for variable or unknown orientation [1]. In case of array antenna, weight and size are two parameters to be kept at mind during design process as some applications require low weight and small size antenna. Microstrip antennas are good candidate to overcome this problem due to its inherent advantages of low profile, light weight, low cost and easy integration with microwave circuits [2]. Conventional array antennas use only microstrip lines to design feed network that lead to complex structure and longer microstrip line length for impedance matching circuit. As a result, antenna structure becomes larger and performance degrades due to higher feeding loss and cross polarized radiation [3]. Use of double-sided MIC concept that gives flexibility to put different types of transmission lines on the both sides of the substrate can be used to design small sized array antenna by overcoming these problems [4].

There are two main ways to excite circular polarization radiation. A microstrip patch element can be used to achieve circular polarization radiation by means of a perturbation segment. Sveral structures for a circularly polarized antenna using perturbation technique have been studied [5-9]. In [5], a method is reported to design circular polarized rectangular microstrip antenna with one point feed where feed point is located either on $\mathrm{x}$ axis or on the diagonal line of the patch. Truncating a pair of patch corners in rectangular or square patch for $\mathrm{CP}$ is discussed in [6]. An antenna with slits or spur lines to the boundary of the patch is reported in [7-8]. Design of trapezoidal shape slot antenna excited by CPW line is shown in [9]. Dualorthogonal feed technique is another way to generate $\mathrm{CP}$ where two separate orthogonal feeds are excited 
with a $90^{\circ}$ phase difference. Dual feed CP antennas have been presented in $[2,10]$. On the other hand, single feed or dual feed antennas can be arrayed [11-15]. A serial feed sequentially rotated technique is used to design a CP array antenna [11] where each patch element is single feed. In this array, complete feed network is designed using microstrip lines. A CP slot array antenna with orthogonal feed is presented in [12]. In [1314], single layer microstrip array antennas for CP are proposed where a $90^{\circ}$ hybrid circuit is used to achieve circular polarization. Double-sided MIC technology is used to design the array antennas of [12-14] as the feed network in each array consists of microstrip lines and slot lines. Another 128 elements CP array antenna excited using a 1by 4 corporate feed network of hollow metallic waveguides is demonstrated in [15].

In this paper, a dual-orthogonal feed $1 \times 2$ microstrip array antenna is discussed. The feed network is formed by placing microsrip lines on the obverse side and slot lines on the reverse side of the substrate. Double-sided MIC concept is employed to design feed network successfully. A parametric study is conducted by simulation to optimize the antenna performance. The proposed array antenna has a 3-dB axial ratio bandwidth of $1.85 \%$. The complete antenna structure along with antenna performances is presented and discussed in subsequent sections.

Literature review that has been done author used in the chapter "Introduction" to explain the difference of the manuscript with other papers, that it is innovative, it are used in the chapter "Research Method" to describe the step of research and used in the chapter "Results and Discussion" to support the analysis of the results [2]. If the manuscript was written really have high originality, which proposed a new method or algorithm, the additional chapter after the "Introduction" chapter and before the "Research Method" chapter can be added to explain briefly the theory and/or the proposed method/algorithm [4].

\section{ANTENNA DESIGN}

The complete structure of the array antenna is shown in Figure 1. The antenna is designed on Teflon glass fiber substrate backed by the ground plane. Relative dielectric constant $\left(\varepsilon_{\mathrm{r}}\right)$ of the substrate is 2.15 with a thickness of $0.8 \mathrm{~mm}$. Thickness of the copper sheet used for radiating and ground plane is $0.018 \mathrm{~mm}$. The dimension of the ground plane is $61.35 \times 37.23 \mathrm{~mm}^{2}$.

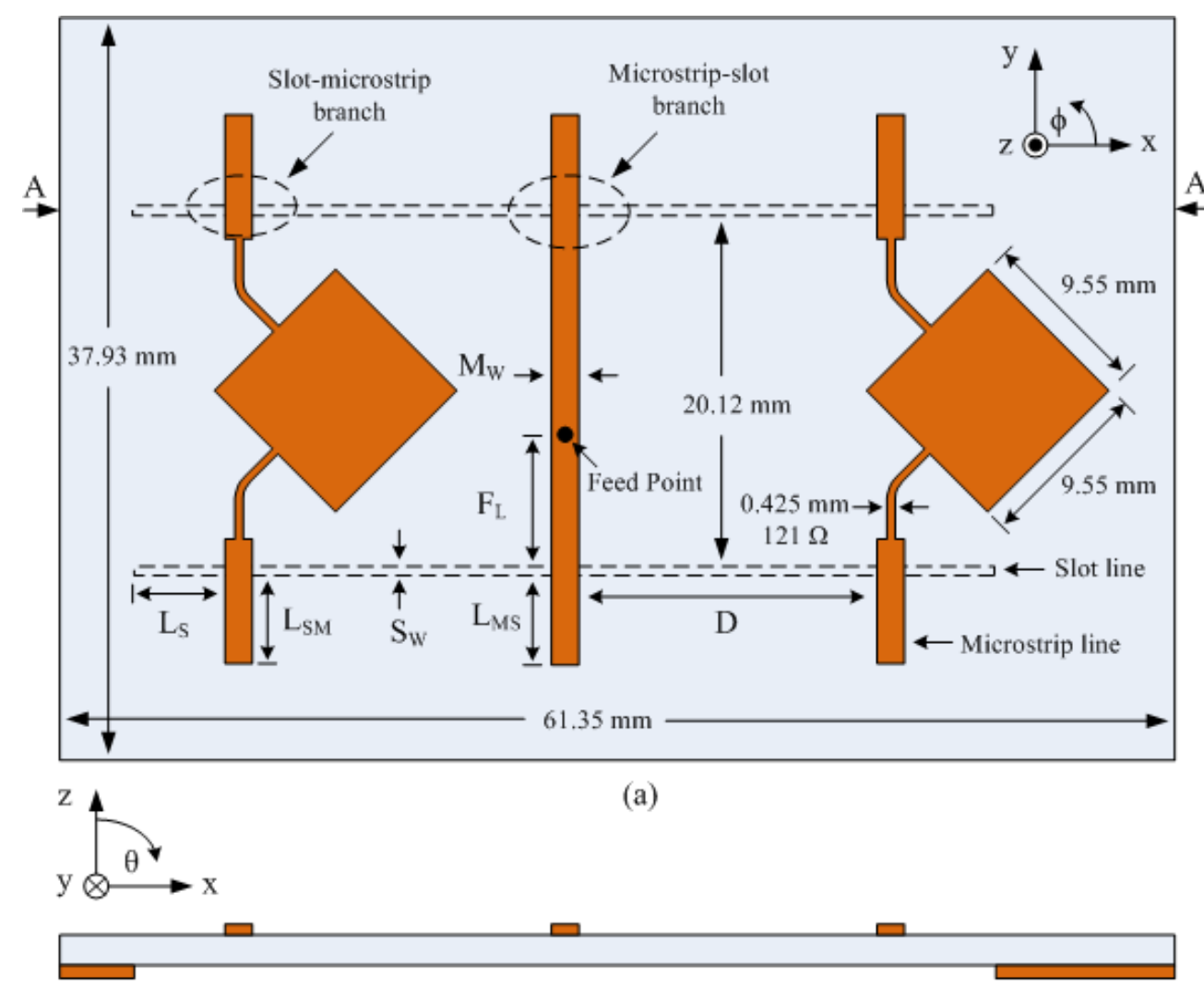

(b)

Figure 1. Complete structure of the $1 \times 2$ array antenna (a) Top view (b) Cross sectional view 
Square microstrip patch is used as radiating element. As the patch length determines the resonant frequency [16], the following equation is used to calculate the patch length and then the width of the patch keeps as same length value because of square patch.

$$
L=\frac{C}{2 f_{r} \sqrt{\varepsilon_{r e}}}-2 \Delta L
$$

Where $\mathrm{C}$ is the velocity of light and $\mathrm{f}_{\mathrm{r}}$ is the resonant frequency.

Due to a fraction of the fields lies outside the physical dimension $(\mathrm{W} \times \mathrm{L})$ of the patch called as the fringing field, the effective patch length $\mathrm{L}_{\mathrm{e}}$ becomes $\mathrm{L}+2 \Delta \mathrm{L}$ and the relative dielectric constant $\varepsilon_{\mathrm{r}}$ is replaced by the effective dielectric constant $\varepsilon_{\mathrm{re}}$. The value of $\varepsilon_{\mathrm{re}}$ can be calculated by the equation given in [17] as

$$
\varepsilon r e=\frac{\varepsilon_{r}+1}{2}+\frac{\varepsilon_{\mathrm{r}}-1}{2}\left[1+10 \frac{h}{W}\right]^{-1 / 2}
$$

where $\mathrm{h}$ is the thickness of the substrate.

Additional line length $\Delta \mathrm{L}$ on either end of the patch length can be obtained from [18] as

$$
\Delta L=0.412 h\left[\frac{\varepsilon_{r e}+0.3}{\varepsilon_{r e}-0.258}\right]\left[\frac{\frac{W}{h}+0.264}{\frac{W}{h}+0.8}\right]
$$

Each side of the patches is set as $9.55 \mathrm{~mm}$ for $10 \mathrm{GHz}$ frequency. The feed network is composed of microstrip lines and slot lines. The double-sided MIC concept is very effective to design this type of feed network and it is successfully employed in this design process. Radiating patches and microstrip lines are placed on the upper surface of the substrate and the slot lines lie on the lower surface of the substrate. The feed network consists of microstrip-slot branch circuit and slot-microstrip branch circuit. For proper impedance matching between microstrip line and slot line, the impedance of microstrip line should be half of the slot line impedance [19]. For a desired characteristic impedance $Z_{C}$, the width of the microstrip line can be calculated by [20] as

$$
\mathrm{W}=h \frac{8 e^{A}}{e^{2 A}-2}
$$

Where $\mathrm{A}=\frac{Z_{c}}{60} \sqrt{\frac{\varepsilon_{r}+1}{2}}+\frac{\varepsilon_{r}-1}{\varepsilon_{r}+1}\left(0.23+\frac{0.11}{\varepsilon_{r}}\right)$ and $\mathrm{B}=\frac{377 \pi}{2 \mathrm{Z}_{\mathrm{c}} \sqrt{\varepsilon_{\mathrm{r}}}}$

For proper matching between the each patch and microstrip line of the slot-microstrip branch circuit, $121 \Omega$ quarter-wave transformer is used that is computed by [21] as

$$
\mathrm{Z}=\sqrt{Z_{0} Z_{i}}
$$

Where $Z_{0}$ is the impedance at feed point of the patch and $Z_{i}$ is the microstrip line impedance of the slot-microstrip branch circuit.

\section{BASIC BEHAVIOR OF THE ARRAY}

To generate circular polarized waves, two orthogonal signals of equal amplitude with $90^{\circ}$ phase shift between them are needed. The basic behavior of the proposed circularly polarized array antenna can be explained using Figure 2. Two separate orthogonal feed Port I and Port II are used to excite two degenerate orthogonal modes in the patches. Moreover, the feed point as shown in figure is chosen in such a way that the signal of the lower feed circuit is ahead by quarter wave length from that of upper feed circuit that create $90^{\circ}$ phase difference between two orthogonal input signal.

When RF signal is supplied to the feed point, the signals are divided in phase to the slot line through the microstrip-slot parallel branches and they are successively divided in out of phase to the microstrip lines

Dual Orthogonal Feed Circular Polarization Array Antenna Using Microstrip Slot ...(Quazi Delwar H.) 
through the slot-microstrip series branches and feed the signals to each patch element. Microstrip-slot branch circuit acts as a parallel power divider with in-phase outputs and slot-microstrip branch is series power divider where outputs are in out of phase [19]. Therefore, in each patch of the array, two orthogonal signals are formed with $90^{\circ}$ phase shift and as a result circularly polarized signal is excited. One interesting thing is that LHCP and RHCP can be excited using same array structure by changing feed point as shown in Figure 2. When feed point is placed at Feed-1, LHCP will be radiated and RHCP can be excited by changing feed point position from Feed-1 to Feed-2.

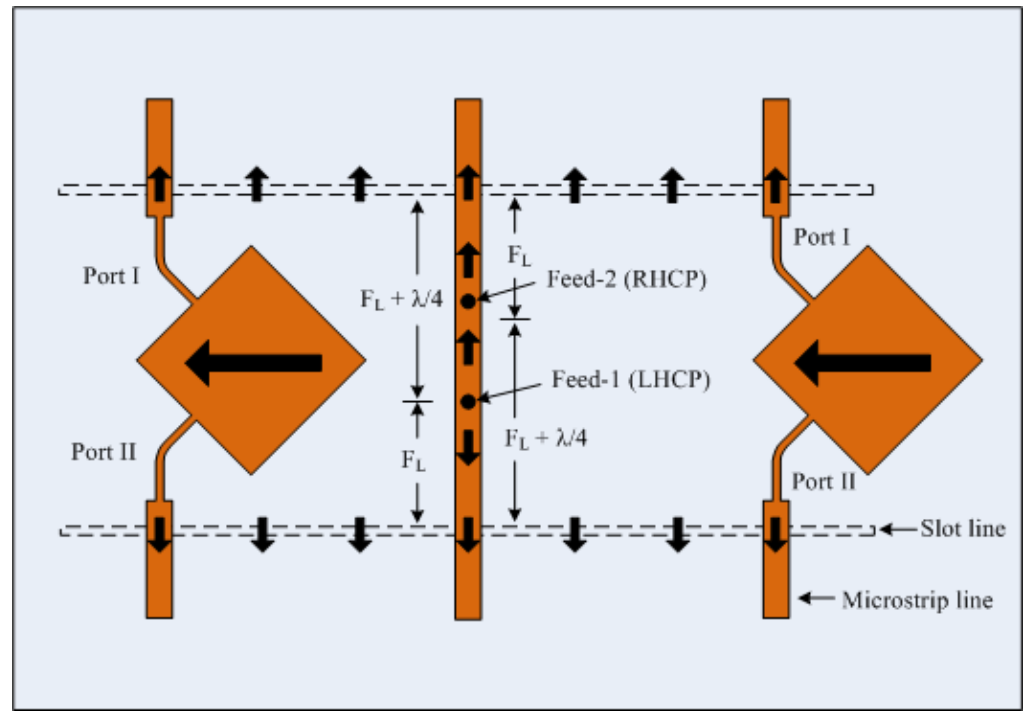

Figure 2. Basic behavior of the array antenna

\section{PARAMETRIC STUDY OF THE ARRAY}

To obtain best performance, the parametric study of the proposed antenna is conducted. Different parameters for parametric study are illustrated in Figure 1. The microstrip line width of the branch circuits denoted by $\mathrm{M}_{\mathrm{W}}$, the spacing between the feed line and the slot-microstrip branch point denoted by $\mathrm{D}$ and the length of the slot line extension from microstrip line in slot-microstrip branch denoted by $\mathrm{L}_{\mathrm{SM}}$ are main three parameters responsible for proper impedance matching.

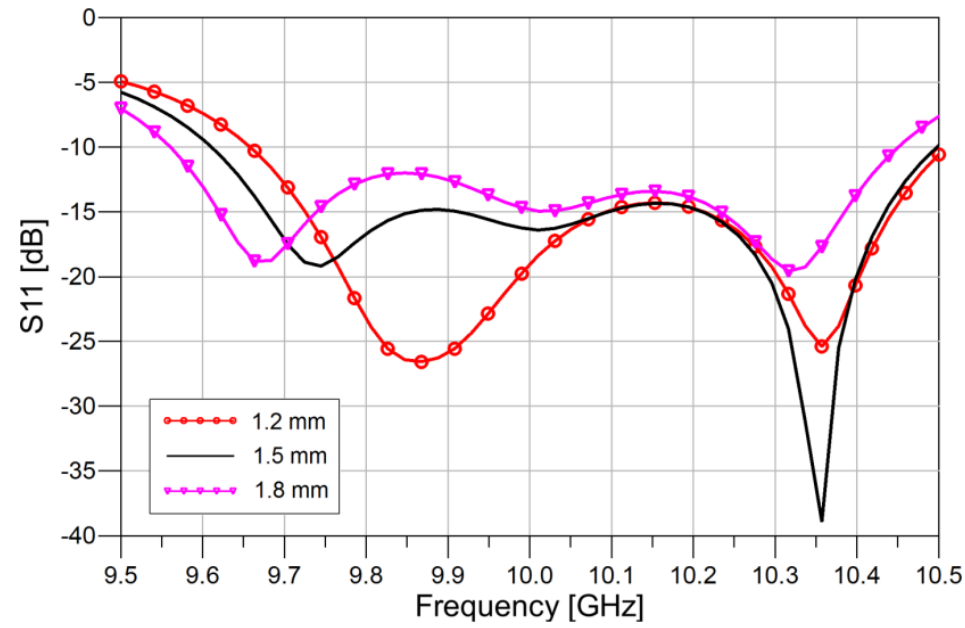

Figure 3. Effect of $\mathrm{M}_{\mathrm{W}}$ on the return loss of the antenna 
Hence, these parameters can be optimized by parametric study. The slot line width $\left(\mathrm{S}_{\mathrm{W}}\right)$ and the position of the feed point $\left(\mathrm{F}_{\mathrm{L}}\right)$ are another two parameters to be studied as they influence both impedance bandwidth and axial ratio. The effects of varying the width of microstrip lines $\left(\mathrm{M}_{\mathrm{W}}\right)$ on the antenna performance are shown in Figure 3. It is observed that the operating bandwidth is shifted left and return loss decreases with increasing the microstrip line width. Figure 4 shows the simulated return loss obtained by changing the spacing between slot-microstrip branch and the feed line when other parameters are fixed. The value of $\mathrm{D}$ changes the operating frequency and the impedance bandwidth is decreased rapidly with increasing the spacing. But at an optimum point, it gives better retun loss value and impedance bandwidth and it is chosen as $16.935 \mathrm{~mm}$.

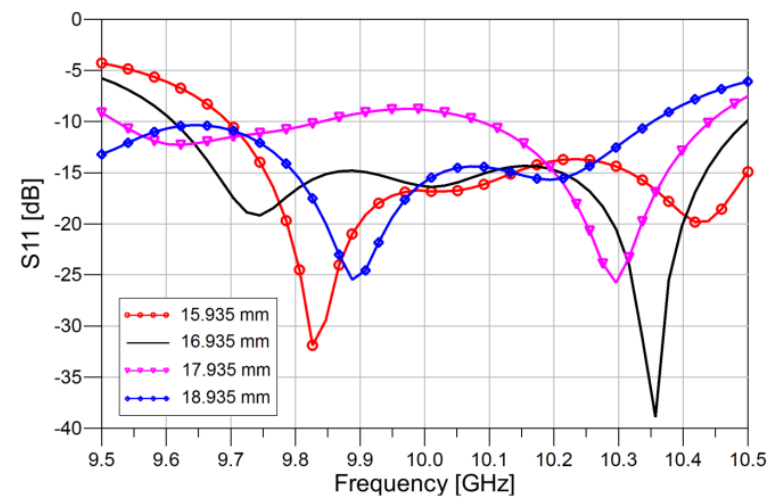

Figure 4. Return loss for different values of D

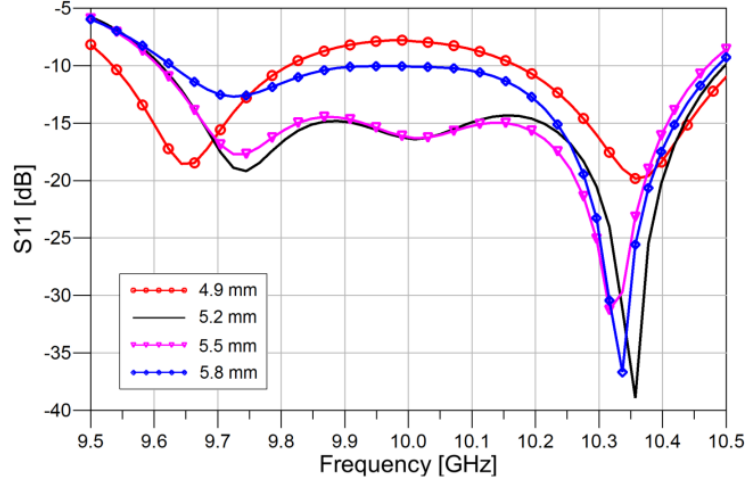

Figure 5. Return loss for different values of $\mathrm{L}_{\mathrm{S}}$

The variation of return loss for different values of $\mathrm{L}_{\mathrm{S}}$ is plotted in Figure 5. The cut-off frequency is almost fixed but impedance bandwidth is reduced when the length is increased. So $\mathrm{L}_{\mathrm{S}}=5.2 \mathrm{~mm}$ is the optimum value that provides higher return loss with best possible impedance bandwidth. Figure 6 shows the effects of varying the length of microstrip line extension of slot-microstrip branch circuit $\left(\mathrm{L}_{\mathrm{SM}}\right)$ for two different values of microstrip line extension of microstrip-slot branch $\left(\mathrm{L}_{\mathrm{MS}}\right)$. When $\mathrm{L}_{\mathrm{MS}}(=5.58 \mathrm{~mm})$ is equal to the value of the wavelength $(\lambda)$ at design frequency, variation of $L_{S M}$ has little effect on the performance of the antenna. But in the case of $\mathrm{L}_{\mathrm{SM}}=\mathrm{L}_{\mathrm{MS}}$, the cut-off frequency is moved from lower frequency to a higher frequency and gives better return loss value.

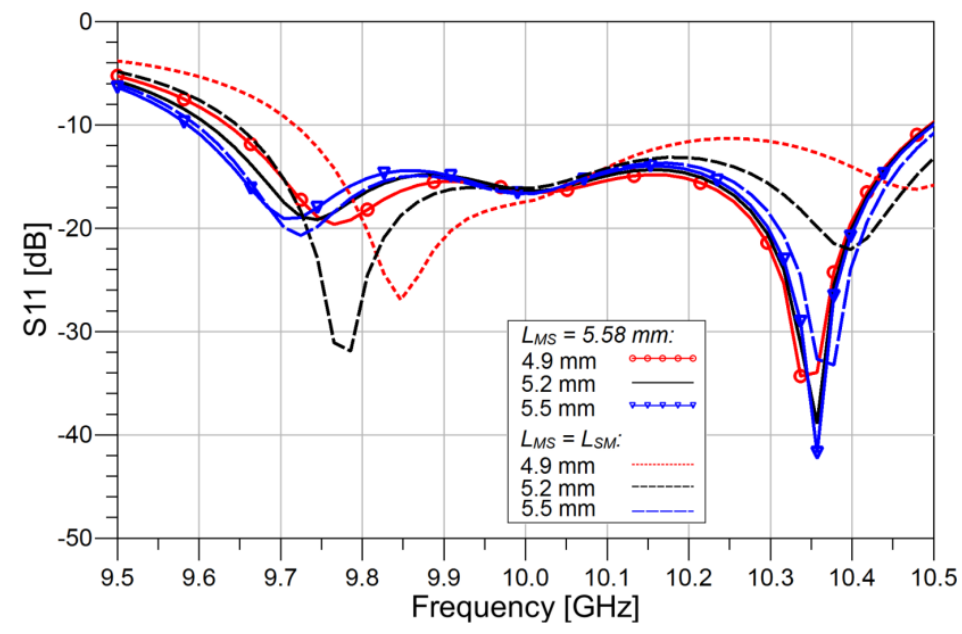

Figure 6. Return loss for different values of $\mathrm{L}_{\mathrm{MS}}$ 


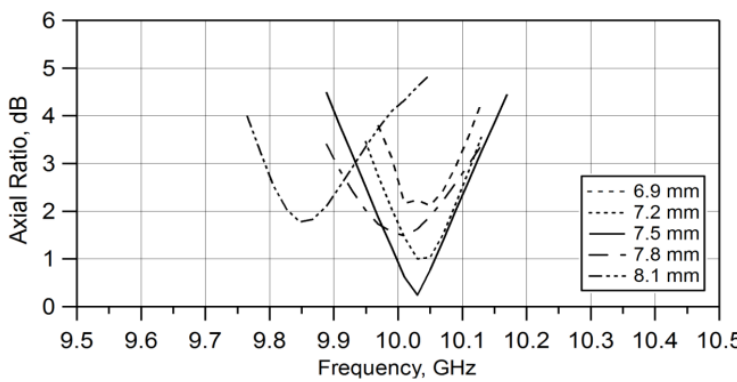

Figure 7. Axial ratio for different feed location $\left(\mathrm{F}_{\mathrm{L}}\right)$

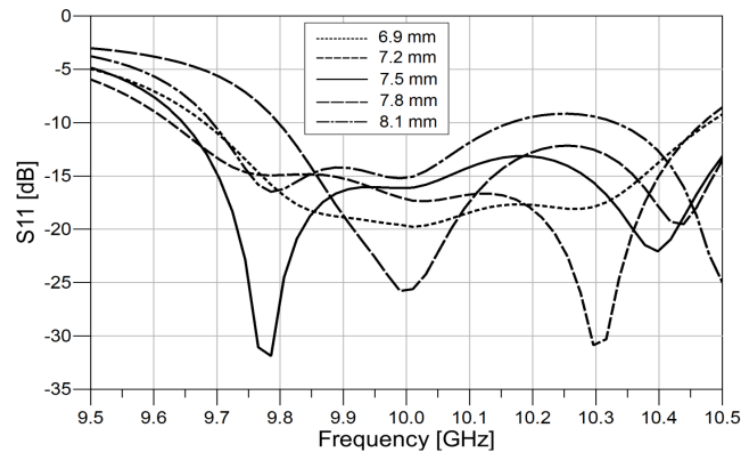

Figure 8. Return loss for different values of $\mathrm{F}_{\mathrm{L}}$

After proper impedance matching, it is required to analysis those parameters which influence the axial ratio bandwidth. Feed point location $\left(\mathrm{F}_{\mathrm{L}}\right)$ is very important parameter that required fine tuning to get optimum axial ratio. Figure 7 and Figure 8 show the axial ratio and return loss for different feed location respectively. Though the position of the feed point shifts the operating frequency bandwidth as shown by Figure 8 but it is also necessary to place feed point in such a location that can create $90^{\circ}$ phase difference between the orthogonal feed signals of the patch. When the position is at the optimum point, the radiation will be perfectly circularly polarized and the axial ratio curve at operating frequency will be approached to a minimum value. The minimum axial ratio of $0.243 \mathrm{~dB}$ is found when $\mathrm{F}_{\mathrm{L}}=7.5 \mathrm{~mm}$ as shown in Figure 7 and it can be taken as an optimum point as it also gives better return loss value.

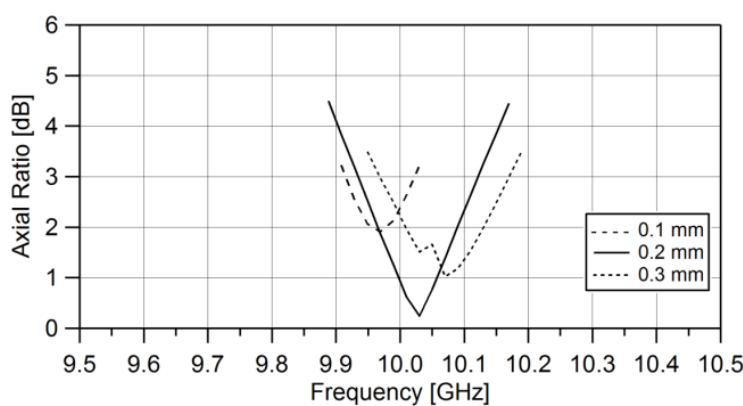

Figure 9. Axial ratio for different values of $S_{W}$

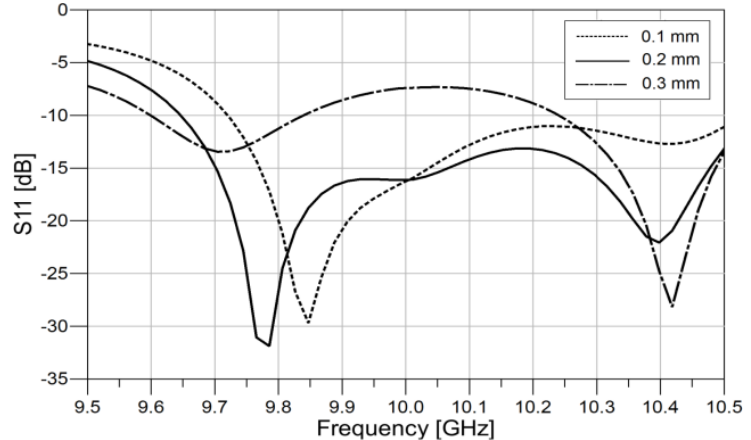

Figure 10. Return loss for different values of $\mathrm{S}_{\mathrm{W}}$

Slot line width should be optimized to get better axial ratio and return loss. Variations of axial ratio and return loss for changing $\mathrm{S}_{\mathrm{W}}$ are shown in Figure 9 and Figure 10 respectively. For fine tuning of axial ratio, it is necessary to adjust slot line width and select an optimum value that will give good axial ratio with better impedance matching. But it is also observed that at a longer width, the axial ratio and return loss again start to decrease. So $\mathrm{S}_{\mathrm{W}}=0.2 \mathrm{~mm}$ is the optimum value to get better performance.

\section{RESULTS AND DISCUSSIONS}

The antenna is designed and simulated using commercial EM software package, Advanced Design System (ADS) based on the Method of Moments (MOM). The optimal dimensions of the antenna obtained by parametric analysis are: $\mathrm{M}_{\mathrm{W}}=1.5 \mathrm{~mm}, \mathrm{~S}_{\mathrm{W}}=0.2 \mathrm{~mm}, \mathrm{D}=16.935 \mathrm{~mm}, \mathrm{~L}_{\mathrm{MS}}=\mathrm{L}_{\mathrm{SM}}=\mathrm{L}_{\mathrm{S}}=5.2 \mathrm{~mm}$ and $\mathrm{F}_{\mathrm{L}}=$ $7.5 \mathrm{~mm}$. Return loss (S11) of the array is shown in Figure 11. The result indicates that the return loss is smaller than $-10 \mathrm{~dB}$ from 9.65 to $10.57 \mathrm{GHz}$. So the impedance bandwidth is $9.1 \%$ with respect to the center frequency of $10.11 \mathrm{GHz}$. Figure 12 shows the axial ratio performance of the proposed antenna. From 9.905 $\mathrm{GHz}$ to $10.09 \mathrm{GHz}$, the axial ratio is below $3 \mathrm{~dB}$ level. So the axial ratio $(\mathrm{AR}<3 \mathrm{~dB})$ bandwidth of the designed array antenna is $185 \mathrm{MHz}$ or about $1.85 \%$ respect to the center frequency of $9.99 \mathrm{GHz}$ and the minimum value of axial ratio is $0.026 \mathrm{~dB}$ at $9.99 \mathrm{GHz}$. This result shows a good axial ratio smaller than $3 \mathrm{~dB}$ at the design frequency and it confirms that the proper circular polarization is achieved. 


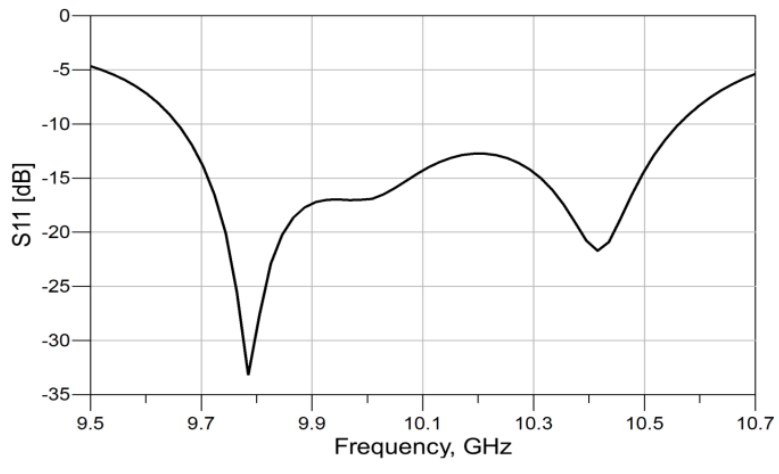

Figure 11. Return loss of the antenna

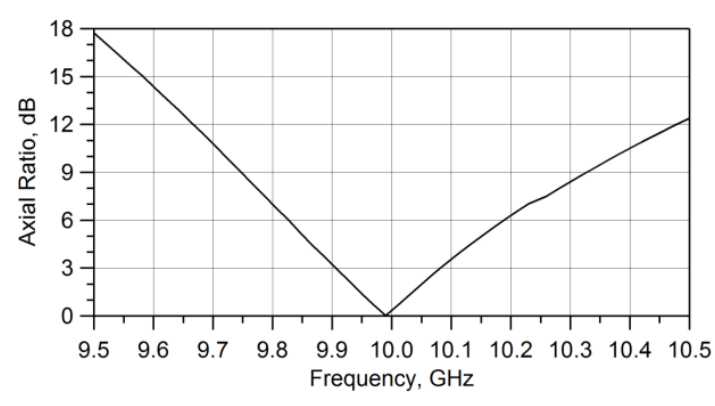

Figure 12. Axial ratio of the antenna

Gain of the array antenna is illustrated in Figure 13. Maximum gain of $9.49 \mathrm{dBic}$ is achieved at 9.91 $\mathrm{GHz}$. It is also observed that average gain over the complete operating bandwidth is higher than 9 dBic. Figure 14 exhibits the radiation pattern of $1 \times 2$ array antenna at $9.99 \mathrm{GHz}$. Figure shows good radiation performance of the array antenna. Antenna radiation is left hand circularly polarized (LHCP). But it is also possible to radiate right hand circularly polarized (RHCP) waves using same antenna structure by changing only feed point. When Feed-2 is used to excite the antenna, input signal of Port I is ahead by quarter wavelength than that of Port II. As a result, the radiation will be RHCP. The cross polar level of the antenna is better than $-45 \mathrm{~dB}$ that indicates very good radiation performance of the antenna. To compare the antenna performance, four previous works are listed in Table 1.

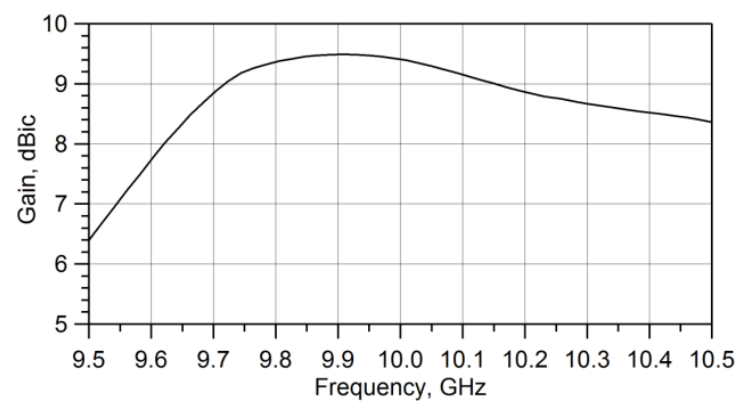

Figure 13. Gain of the array antenna

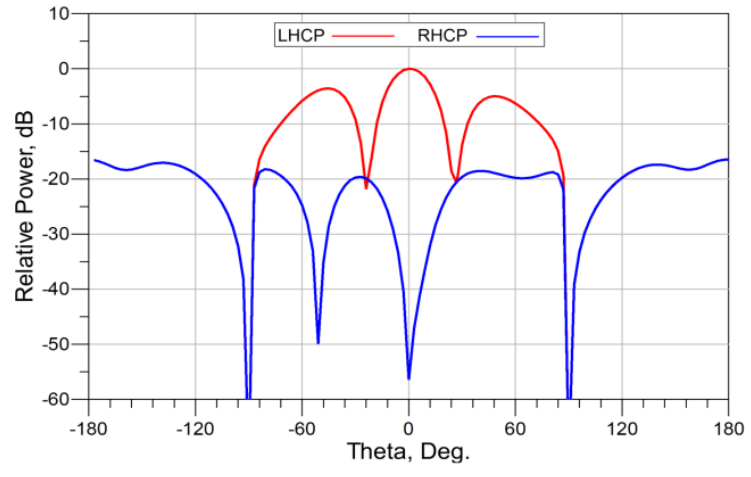

Figure 14. Radiation pattern at $9.99 \mathrm{GHz}$

Table 1. Comparison

\begin{tabular}{|c|c|c|c|c|c|c|}
\hline Ref. No. & Year & Array Size & Frequency, GHz & $\begin{array}{c}\text { Impedance BW }(<- \\
10 \mathrm{~dB})\end{array}$ & $\begin{array}{c}\text { Axial Ratio BW }(<3 \\
\mathrm{dB})\end{array}$ & $\begin{array}{l}\text { Gain, } \\
\text { dBic }\end{array}$ \\
\hline [11] & 2006 & $2 \times 2$ & 2.45 & $0.073 \mathrm{GHz}$ & $0.02 \mathrm{GHz}$ & --- \\
\hline [12] & 2010 & $2 \times 2$ & 7.5 & $1.8 \mathrm{GHz}$ & $12 \%$ & --- \\
\hline [13] & 2012 & $2 \times 2$ & 10 & $\begin{array}{l}1.25 \mathrm{GHz} \\
(<-15 \mathrm{~dB})\end{array}$ & $10 \%$ & 12.5 \\
\hline [14] & 2012 & $2 \times 2$ & 10 & $1.5 \mathrm{GHz}$ & $3.8 \%$ & --- \\
\hline $\begin{array}{l}\text { Proposed } \\
\text { Antenna }\end{array}$ & 2014 & $1 \times 2$ & 10 & $0.92 \mathrm{GHz} / 9.1 \%$ & $0.185 \mathrm{GHz} / 1.85 \%$ & 9.49 \\
\hline
\end{tabular}

\section{CONCLUSIONS}

A new dual-orthogonal feed circularly polarized microstrip array antenna at $10 \mathrm{GHz}$ has been demonstrated in this paper. Microstrip lines and slot lines are used to design antenna feed network with the help of double-sided MIC concept and this feed network eliminates the use of any types of power divider or hybrid circuits. Parametric analysis has been done to optimize the antenna parameters. Impedance bandwidth $(<-10 \mathrm{~dB})$ and axial ratio bandwidth $(<3-\mathrm{dB})$ of the array antenna are $9.1 \%$ and $1.85 \%$ respectively. Antenna 
shows high gain all over the operating bandwidth and maximum gain is $9.49 \mathrm{dBic}$ at $9.91 \mathrm{GHz}$. Excellent radiation performance is also observed where cross polar component is lower than $-45 \mathrm{~dB}$. Due to the excellent radiation performance and high gain, the proposed antenna is suitable for many microwave application such portable radar, RF sensors, RFID etc.

\section{REFERENCES}

[1] J. Garcia, A. Arriola, F. Casado, X. Chen, J. I. Sancho, and D. Valderas, "Coverage and read range comparison of linearly and circularly polarized radio frequency identification ultra-high frequency tag antennas", IET Microwaves, Antennas and Propagation, vol. 6, no. 9, pp.1070-1078, 2012.

[2] J.Q. Howell, "Microstrip antennas", IEEE Trans. on Antennas and propagation, vol. 23, no. 1, pp. 90-93, 1975.

[3] K. Kodama, E. Nishiyama and M. Aikawa, "Slot array antenna using both-sided MIC technology", IEEE International symposium on Antennas and Propagation, vol. 3, pp. 2715-2718, 2004.

[4] M. Aikawa, H. Ogawa, "Double-sided MIC's and their applications", IEEE Trans. Microw. Theory Tech., vol. 37, no. 2, pp. 406-413, 1989.

[5] M. Haneishi and S. Yoshida, "A design method of circularly polarized rectangular microstrip antenna by one-point method", Electronics and Communications in Japan, vol. 64-B, no. 4, pp. 46-54, 1981.

[6] W.S. Chen, C.K. Wu, and K.L. Wong, "Single-feed square-ring microstrip antenna with truncated corners for compact circular polarization operation", Electron. Lett., vol. 34, pp. 1045-1047, 1998.

[7] J.H. Lu, C.L. Tang, and K.L. Wong, "Circular polarization design of a single-feed equilateral-triangular microstrip antenna", Electron. Lett., vol. 34, pp. 319-321, 1998.

[8] H.M. Chen and K.L. Wong, "On circular polarization design of annular-ring microstrip antennas", IEEE Trans. on Antennas and Propagation, vol. 47, pp. 1289-1292, 1999.

[9] R.V.S.R. Krishna and R. Kumar, "Design of ultra wideband trapezoidal shape slot antenna with circular polarization”, Int. J. Electron. Commun., vol. 67, pp. 1038-1047, 2013.

[10] G.G. Sanford, "Conformal microstrip phased array for aircraft tests with ATS-6", IEEE Trans. on Antennas and propagation, vol. AP-26, no. 5, pp. 642-646, 1978.

[11] M.N. Jazi and M.N. Azarmanesh, "Design and implementation of circularly polarized microstrip antenna array using a new serial feed sequentially rotated technique", IEE Proc. Microw. Antennas Propag., vol. 153, no. 2, pp. 133-140, 2006.

[12] Y. Ushijima, S. Feng, E. Nishiyama and M. Aikawa, "A Novel Circular Polarization Switchable Slot-Ring Array Antenna with Orthogonal Feed Circuit”, Asia-Pacific Microwave Conference (APMC), pp. 1569-1572, 2010.

[13] Y. Ushijima, E. Nishiyama and M. Aikawa, "Single-layer integrated microstrip array antenna for dual circular polarisation”, IET Microw. Antennas and Propag., Vol. 6, Issue 8, pp. 962-968, 2012.

[14] Y. Ushijima, E. Nishiyama, I. Toyoda and M. Aikawa, "Circular polarization switchable single layer microstrip array antenna", IEEE International Symposium Antennas and Propagation Society (APSURSI), pp. 1-2, 2012.

[15] M. Shahabadi, D. Busuioc, A. Borji and S. Safavi-Naeini, "Low-cost, high-efficiency quasi-planar array of waveguide-fed circularly polarized microstrip antennas", IEEE Transactions on Antennas and Propagation, vol. 53, no. 6, pp. 2036-2043, 2005

[16] R. Garg, P. Bhartia, I. Bhal, and A. Ittipiboon, Microstrip Antenna Design Handbook, Artech House, London, 2001.

[17] M.V. Schneider, "Microstrip dispersion”, Proc. IEEE, vol. 60, no. 1, pp. 144-146, 1972.

[18] E.O. Hammerstad, "Equations for microstrip circuit design", 5th European Microwave Conf., pp. 268-272, 1975.

[19] K. Egashira, E. Nishiyama and M. Aikawa, "Planar array antenna using both-sided MIC's feeded circuits", Electronics and Communications in Japan, vol. 87, no. 7, pp. 23-30, 2004.

[20] David M. Pozar, Microwave Engineering, 3rd edition, John Wiley \& Sons, Inc., 2005.

[21] Matthew N.O. Sadiku, "Elements of Electromagnetics", 3rd edition, Oxford University Press, New York, 2005.

\section{BIOGRAPHIES OF AUTHORS}

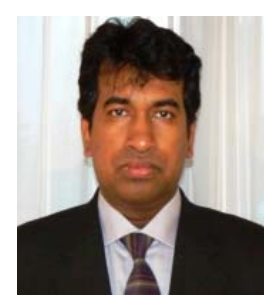

Quazi Delwar Hossain (MIEEE) was born in Barisal, Bangladesh, in 1976. He received the B.Sc. degree in electrical and electronic engineering from Chittagong University of Engineering and Technology (CUET), Chittagong, Bangladesh, in 2001; the Master of Engineering degree in semiconductor electronics and integration sciences from Hiroshima University, Hiroshima, Japan, in 2007; and the Ph.D. degree in microelectronics from the University of Trento, Trento, Italy, in 2010. During his Ph.D. program, he also spent a period with the SOI Group, Bruno Kessler Foundation, Trento, Italy as a Postgraduate Researcher. From 2001 to 2007, he was with CUET as a Lecturer. In 2007, he became an Assistant Professor with the Faculty of Electrical and Computer Engineering, CUET. Presently he is working as an Associate Professor at the Institution. His research interests include image sensors, antenna design and related readout circuit simulation and experimental characterization of semiconductor devices, sensors and photovoltaic cells. 


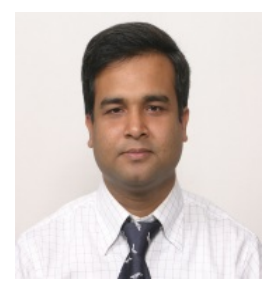

Md. Azad Hossain (MIEEE) was born in Dhaka, Bangladesh, in 1981. He received the B.Sc. degree in Electrical and Electronic Engineering from Rajshahi University of Engineering and Technology (RUET), Rajshahi, Bangladesh, in 2004. The Master of Engineering degree in EEE from Saga University, Saga, Japan, in 2010; and the Ph.D. degree in Science and advanced Technology, in 2013 from the same Institute. From 2013 to 2014, he was with Chittagong University of Engineering and Technology (CUET) as a Lecturer. Presently he is working as an Assistant Professor at CUET. His research interests include Microwave antenna design and related readout circuit simulation and experimental characterization.

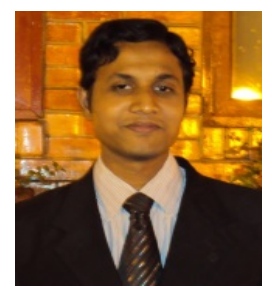

Muhammad Asad Rahman was born in Chittagong, Bangladesh, on October, 1986. He received his B.Sc. degree in Electrical and Electronic Engineering from Chittagong University of Engineering and Technology (CUET), Bangladesh in 2009. Currently he is perusing M.Sc. degree on large scale extensible microstrip array antenna and also working as a faculty member in CUET, Bangladesh. His field of interest is microstrip antenna design, polarization diversity techniques, wireless power transfer and next generation wireless communication system. He is a student member of IEEE and member of Institute of Engineers, Bangladesh. 